\title{
Analysis of metals leached from smoked cigarette litter
}

\author{
J W Moerman, ${ }^{1}$ G E Potts ${ }^{2}$
}

- Additional materials are published online only. To view these files please visit the journal online (http:// tobaccocontrol.bmj.com).

${ }^{1}$ School of Earth and Atmospheric Sciences, Georgia Institute of Technology, Atlanta, Georgia, USA

${ }^{2}$ Department of Chemistry, The University of Tennessee at Chattanooga, Chattanooga, Tennessee, USA

\section{Correspondence to}

Dr Gretchen E Potts,

Department of Chemistry, The University of Tennessee at Chattanooga, 615 McCallie Avenue, \#2252, Chattanooga, TN 37403, USA;

gretchen-potts@utc.edu

Received 19 September 2010 Accepted 25 January 2011
ABSTRACT

Background Littered cigarette butts represent potential point sources for environmental contamination. In areas with substantial amounts of cigarette litter, environmental hazards may arise as chemical components are leached from the filters and smoked tobacco.

Objective The three main aims of this study were: (1) to quantify the amount of $\mathrm{Al}, \mathrm{Ba}, \mathrm{Cd}, \mathrm{Cr}, \mathrm{Cu}, \mathrm{Fe}, \mathrm{Pb}, \mathrm{Mn}, \mathrm{Ni}$, $\mathrm{Sr}, \mathrm{Ti}$ and $\mathrm{Zn}$ leached from cigarette butts, (2) to determine the relationship between the $\mathrm{pH}$ of the aqueous soaking solution and metal concentration leached and (3) to determine the relationship between the period of soaking in aqueous solution and metal concentration leached.

Methods Smoked cigarette butts and unsmoked cigarettes were added to phials containing aqueous solutions of $\mathrm{pH} 4.00,5.00$ and 6.00 ( \pm 0.05$)$. The metal concentration of the resultant leachates was measured via inductively coupled plasma optical emission spectroscopy (ICP-OES) 1 day, 7 days and 34 days after sample addition.

Results All metals were detected in leachates 1 day after sample addition (with the exception of $\mathrm{Cd}$ ) and were released at varying rates. No clear relationship between $\mathrm{pH}$ within the range typical of precipitation and metal concentration leached was observed.

Conclusions Based on the gradual release of multiple metals over the full 34-day study period, cigarette litter was found to be a point source for metal contamination. The apparent rapid leaching of other metals may increase the risk of acute harm to local organisms.

Cigarette butts are among the most common forms of litter. Worldwide, approximately 4.95 trillion cigarette butts are estimated to be littered each year. ${ }^{1}$ Of the 10 million pieces of litter collected during the 2009 International Coastal Cleanup campaign, 21\% were cigarette butts and filters, ${ }^{2}$ twice as much as any other type of litter. Water channelled by sewer systems and streams acts to accumulate cigarette litter in localised areas and leach its chemical components into the environment. Although many may argue that a single piece of cigarette litter would not inflict serious environmental damage, the cumulative effect of many cigarette butts littered in a centralised area may present a significant threat to local organisms. Indeed, several studies ${ }^{3-5}$ have found cigarette litter toxic to some aquatic species.

Although the compounds in cigarettes and mainstream smoke have been extensively researched, few studies have attempted to identify and quantify the components leached from cigarette butts ${ }^{3}$ or assess the leaching behaviour of these components. Micevka et al. ${ }^{3}$ suggest that the toxicity of cigarette butt leachates is in part due to heavy and trace metals. The occurrence of metals in cigarettes can largely be attributed to the growth and cultivation of tobacco (Nicotiana tabacum), as tobacco is known to readily accumulate metals from underlying soil. ${ }^{7}$ The metal composition of soil primarily reflects the mineral composition of the bedrock from which it was derived. Fertilisers, however, may also introduce metals to soil. Case studies of the use of municipal sludge containing heavy metals as fertiliser found significant increases in the concentration of many heavy metals in the sludge-amended soils and the plants grown in these soils. ${ }^{7}$ The application of pesticides, insecticides and herbicides also introduce metals to the tobacco leaf. ${ }^{8}$ Further introduction occurs during cigarette manufacture, particularly via the addition of casing materials to the cured leaves ${ }^{9} 10$ and the use of brightening agents on the wrapping paper. ${ }^{11-13}$

The response of biota to metal contamination is highly varied. ${ }^{14} 15$ Whereas increased levels of trace and heavy metals in soils and water adversely affect some organisms, contamination enhances the metal tolerance of other species (eg, bioaccumulators). Environmental conditions, such as $\mathrm{pH}$, further vary biological responses to contamination by affecting the mobility of metals in soils and the bioavailability of metals to plants. ${ }^{14}$ To better predict how metals leached from littered cigarette butts affect local biota, investigation of their leaching behaviour is required. The main aims of this study, therefore, were: (1) to determine the concentration of $\mathrm{Al}, \mathrm{Ba}, \mathrm{Cd}, \mathrm{Cr}, \mathrm{Cu}, \mathrm{Fe}, \mathrm{Mn}, \mathrm{Ni}, \mathrm{Pb}$, $\mathrm{Sr}, \mathrm{Ti}$ and $\mathrm{Zn}$ leached from cigarette butts in aqueous solution; (2) to assess the relationship between $\mathrm{pH}$ of the leaching solution and metal concentration leached; and (3) to assess the relationship between soaking time and metal concentration leached. The metals listed above were selected for study based on their presence in smoked filters, ${ }^{12}{ }^{16}{ }^{17}$ toxicity to living organisms, ${ }^{18}$ and/or ability to be reliably analysed by inductively coupled plasma optical emission spectroscopy (ICP-OES).

\section{METHODS \\ Sampling}

Smoked cigarette butts were collected from covered cigarette receptacles adjacent to buildings on the campus of the University of TennesseeChattanooga, USA. Following collection, the filters were manually separated from the remnant tobacco on the cigarette butts. These components were stored separately in disposable plastic containers. unlocked scheme, see http:// tobaccocontrol.bmi.com/site/ about/unlocked.xhtml 
Cigarette butts were not collected after local precipitation events to reduce the loss of analyte prior to sampling. Packs of the three most popular cigarette brands in the USA ${ }^{19}$ were also purchased from convenience stores. The unsmoked cigarettes were stored in their original packaging and sealed inside a disposable plastic container to prevent moistening caused by humidity in the laboratory.

\section{Leaching procedure}

Aqueous solutions were prepared by adding dilute analytical grade sulfuric acid and/or ammonium hydroxide dropwise to deionised water. The $\mathrm{pH}$ of the solutions (6.00, 5.00 and 4.00) was determined within \pm 0.05 of the desired unit with a Vernier LabQuest pH probe (Beaverton, OR, USA). Aliquots (100 ml) were transferred to $125 \mathrm{ml}$ high-density polyethylene (HDPE) phials. Leachates of smoked cigarette material were prepared by adding approximately $2.0 \pm 0.2 \mathrm{~g}$ filter and $2.0 \pm 0.2 \mathrm{~g}$ remnant tobacco to the phials of aqueous solution. Leachates of unsmoked cigarette material were prepared by adding $3.6 \pm 0.1 \mathrm{~g}$ of unsmoked cigarettes (approximately four whole cigarettes) to the phials of aqueous solution. The cigarette material was allowed to soak in the aqueous solutions for 1 day, 7 days and 34 days. Individual phials designated for each soaking period were prepared to avoid changes in the volume of the leaching solution after successive analyses. This procedure is summarised in figure 1. Method blanks were prepared in the same manner as the leachate samples except no cigarette material was added.

\section{Filtration and ICP-OES analysis}

The leachates were extracted 1 day, 7 days and 34 days after sample addition using Luer-lock ${ }^{\mathrm{TM}}$ syringes. Nylon filter tips $(0.22 \mu \mathrm{m})$ were attached to the syringes to allow direct filtration into test tubes for analysis. A new filter (conditioned by the sample leachate) was used for each sample. The concentration of each metal in the leachates was measured by ICP-OES. The operating conditions of the Jobin-Yvon Ultima ICP-OES (Edison, NJ, USA) are given in table S1, and the emission wavelengths of each metal are listed in table S2 (see Supplementary material).

\section{RESULTS}

\section{Metals leached from cigarette material}

All 12 of the metals selected for analysis were identified in quantifiable amounts in the leachates after 1 day of soaking with the exception of cadmium in the smoked cigarette leachates (tables 1 and 2). Detection limits, based on 2SD of the analytical

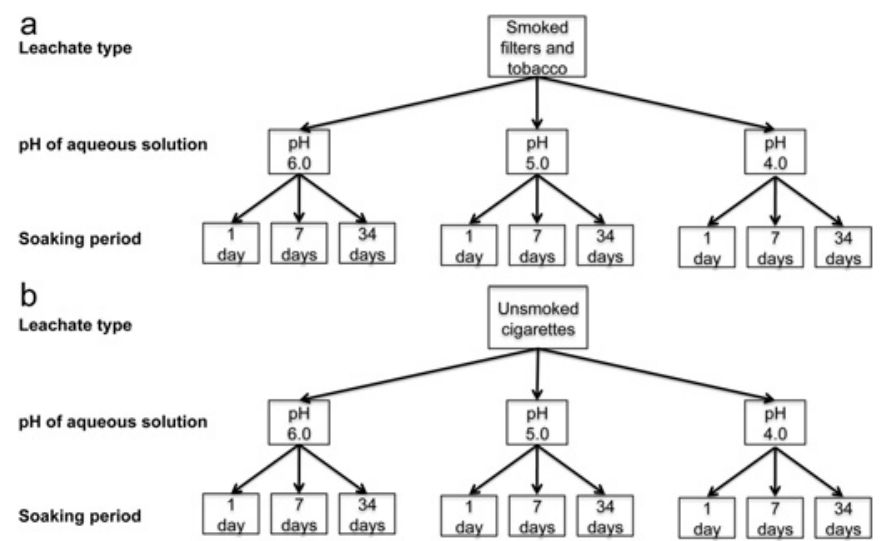

Figure 1 Schematic of leaching procedure for leachates derived from (A) smoked cigarette material and (B) unsmoked cigarettes. blank, ranged between $0.03 \mu \mathrm{g} /$ litre $(\mathrm{Ba})$ and $8 \mu \mathrm{g} /$ litre $(\mathrm{Al})$ and are given in table S2. The concentration of metal leached was converted to $\mu g_{\text {analyte }} / g_{\text {sample added }}$ to account for variation in sample mass added. Data that failed a 90\% CI t-test were excluded from the data set, resulting in sample sets of varying sizes. The average concentration of metal leached varies from values below limits of detection (Cd, 1-day analysis, smoked material) to over $75 \mu \mathrm{g} / \mathrm{g}$ (Fe, 34-day analysis, unsmoked material)

\section{Metal concentration and $\mathrm{pH}$}

Within the $\mathrm{pH}$ range studied, no identifiable trend emerged between $\mathrm{pH}$ of the aqueous leaching solution and metal concentration leached from the smoked cigarette material (figure 2). Analysis of variance (ANOVA) statistical tests were performed to determine whether the concentration of metal leached varied significantly with $\mathrm{pH}$. The results of these tests indicate that in almost all cases, the difference in the metal concentration leached with $\mathrm{pH}$ is due to random error. Based on this conclusion, the concentration of metal leached for each soaking period presented in tables 1 and 2 incorporates samples from each $\mathrm{pH}$ group.

\section{Metal concentration and soaking period}

Variable relationships between soaking time and metal concentration leached from the smoked cigarette material were observed (figure 3). The concentration of $\mathrm{Ba}, \mathrm{Fe}, \mathrm{Mn}$ and $\mathrm{Sr}$ leached increased with soaking time, indicating an increase in metal contamination over time. The concentration of $\mathrm{Ni}, \mathrm{Pb}, \mathrm{Ti}$ and $\mathrm{Zn}$ did not change significantly after 1 day of soaking, suggesting all leachable $\mathrm{Ni}, \mathrm{Pb}, \mathrm{Ti}$ and $\mathrm{Zn}$ was released within 1 day. The concentration of $\mathrm{Al}, \mathrm{Cd}, \mathrm{Cr}$ and $\mathrm{Cu}$ leached was found to decrease at some point during the time study. The formation of insoluble compounds and complexes is likely responsible for the observed decrease since solids were removed from the leachates by filtration prior to analysis.

\section{DISCUSSION}

The sampling and leaching procedures used in this study were designed to simulate natural conditions as closely as possible. Littered cigarette butts found in the environment encompass a wide range of cigarette brands with varying amounts of tobacco left on the filters. In this study, smoked cigarette material was collected from actively used butt receptacles to provide a sample population representative of the local cigarette litter with respect to brand and amount of remnant tobacco. A disadvantage of this sampling technique is the introduction of additional variables, as previous work ${ }^{16} 20$ demonstrates that metal concentrations in cigarettes may vary between brands. The percentage relative standard deviation associated with the mean concentration of metal leached given in tables 1 and 2, however, is relatively low for most sample sets, demonstrating the reproducibility of this method. By collecting smoked samples from butt receptacles, the use of human subjects was also made unnecessary.

The leaching procedure employed in this preliminary study simulates a closed system environment. Although an open system is likely more representative of natural conditions, a closed system was considered the most straightforward method of obtaining the maximum amount of leachable metal. For the investigation of how $\mathrm{pH}$ affects the leaching behaviour of the metals studied, a $\mathrm{pH}$ range of 6.00-4.00 was selected for the aqueous solutions because it represents the range of $\mathrm{pH}$ typically observed in natural rainwater. ${ }^{21}$ Indeed, the $\mathrm{pH}$ of 
Table 1 Concentration of metals leached from unsmoked cigarette material measured after specified period of soaking

\begin{tabular}{|c|c|c|c|c|c|c|c|c|c|c|c|c|}
\hline & \multicolumn{12}{|c|}{ Unsmoked cigarette material, $\mu \mathrm{g} / \mathrm{g}$} \\
\hline & $\overline{\mathrm{Al}}$ & $\mathrm{Ba}$ & Cd & $\mathrm{Cr}$ & $\mathrm{Cu}$ & $\mathrm{Fe}$ & Mn & $\mathrm{Ni}$ & $\mathbf{P b}$ & $\mathrm{Sr}$ & $\mathrm{Ti}$ & $\mathrm{Zn}$ \\
\hline \multicolumn{13}{|l|}{1 day } \\
\hline Mean value & 5.94 & 6.45 & 0.130 & 0.326 & 3.74 & 13.8 & 46.4 & 0.480 & 1.36 & 14.1 & 0.603 & 11.1 \\
\hline Error* & \pm 0.73 & \pm 0.46 & \pm 0.02 & \pm 0.019 & \pm 0.38 & \pm 1.8 & \pm 4.2 & \pm 0.07 & \pm 0.10 & \pm 1.7 & \pm 0.037 & \pm 1.1 \\
\hline Minimum value & 5.13 & 5.76 & 0.105 & 0.306 & 3.23 & 12.0 & 41.8 & 0.387 & 1.24 & 11.7 & 0.559 & 9.9 \\
\hline Maximum value & 7.49 & 7.05 & 0.166 & 0.360 & 4.38 & 17.9 & 54.8 & 0.585 & 1.54 & 15.6 & 0.671 & 13.1 \\
\hline RSD (\%) & 12 & 6.6 & 19 & 5.1 & 9.8 & 13 & 8.7 & 15 & 7.2 & 12 & 5.4 & 9.6 \\
\hline $\mathrm{n}$ & 9 & 9 & 7 & 8 & 9 & 9 & 9 & 9 & 9 & 10 & 11 & 9 \\
\hline \multicolumn{13}{|l|}{7 days } \\
\hline Mean value & 6.94 & 10.1 & 0.123 & 0.372 & 1.58 & 30.3 & 54.0 & 0.554 & 1.53 & 20.2 & 0.712 & 11.6 \\
\hline Error* & \pm 0.36 & \pm 0.8 & \pm 0.010 & \pm 0.014 & \pm 0.18 & \pm 3.4 & \pm 3.4 & \pm 0.044 & \pm 0.06 & \pm 0.8 & \pm 0.027 & \pm 0.6 \\
\hline Minimum value & 6.52 & 8.9 & 0.114 & 0.361 & 1.39 & 23.3 & 49.7 & 0.483 & 1.46 & 19.4 & 0.686 & 10.3 \\
\hline Maximum value & 7.39 & 10.9 & 0.140 & 0.385 & 1.83 & 33.4 & 57.7 & 0.611 & 1.61 & 21.1 & 0.741 & 12.3 \\
\hline RSD (\%) & 4.3 & 6.9 & 8.0 & 2.5 & 11 & 11 & 5.6 & 7.5 & 3.0 & 2.7 & 2.6 & 4.8 \\
\hline $\mathrm{n}$ & 7 & 8 & 5 & 11 & 9 & 9 & 10 & 8 & 11 & 9 & 9 & 9 \\
\hline \multicolumn{13}{|l|}{34 days } \\
\hline Mean value & 6.90 & 15.3 & 0.132 & 0.283 & 0.67 & 75.3 & 59.6 & 0.404 & 1.79 & 32.8 & 0.729 & 9.68 \\
\hline Error* & \pm 0.3 & \pm 1.3 & \pm 0.038 & \pm 0.105 & \pm 0.20 & \pm 5.7 & \pm 2.9 & \pm 0.231 & \pm 0.40 & \pm 1.5 & \pm 0.036 & \pm 0.71 \\
\hline Minimum value & 6.59 & 13.8 & 0.092 & 0.197 & 0.48 & 69.2 & 55.8 & 0.171 & 1.34 & 31.8 & 0.689 & 8.82 \\
\hline Maximum value & 7.27 & 18.2 & 0.176 & 0.429 & 1.12 & 84.7 & 62.2 & 0.755 & 2.55 & 35.2 & 0.775 & 10.7 \\
\hline RSD (\%) & 4.2 & 8.1 & 29 & 37 & 30 & 7.0 & 3.9 & 57 & 22 & 3.5 & 4.1 & 6.8 \\
\hline $\mathrm{n}$ & 8 & 9 & 7 & 10 & 10 & 9 & 10 & 9 & 9 & 9 & 9 & 11 \\
\hline
\end{tabular}

*Error represents square root of the sum of the squared relative errors of the mean concentration $(1 \sigma)$ and mass.

$\mathrm{RSD}$, relative standard deviation.

rainfall in the Chattanooga, Tennessee area in 2009 was approximately $4.8-5.0 .^{22}$

As illustrated in figure 2, the findings of this study suggest that differences in $\mathrm{pH}$ within the range typical of precipitation have no appreciable effect on the metal concentration leached from smoked cigarette material. This result implies that changes to the $\mathrm{pH}$ of precipitation within its natural range likely will not enhance or reduce the magnitude of metal contamination from cigarette litter. Further investigation, however, is required to determine the effect of $\mathrm{pH}$ values outside the natural range of precipitation, such as those measured in areas with highly acidic rain.

Further, this study finds that the metals studied have different leaching behaviours over time (figure 3). The direct relationship between soaking period and the concentration of $\mathrm{Ba}, \mathrm{Fe}, \mathrm{Mn}$ and Sr leached indicates that a piece of cigarette litter is a point source of $\mathrm{Ba}, \mathrm{Fe}, \mathrm{Mn}$ and $\mathrm{Sr}$ contamination for at least a month and possibly longer. This result suggests that the longer cigarette litter remains in the environment, the greater the contamination of these metals will be. This finding supports the need for timely

Table 2 Concentration of metals leached from smoked cigarette material measured after specified period of soaking

\begin{tabular}{|c|c|c|c|c|c|c|c|c|c|c|c|c|}
\hline & \multicolumn{12}{|c|}{ Smoked cigarette material, $\mu \mathrm{g} / \mathrm{g}$} \\
\hline & Al & $\mathrm{Ba}$ & Cd & $\mathrm{Cr}$ & Cu & $\mathrm{Fe}$ & Mn & $\mathrm{Ni}$ & $\mathbf{P b}$ & $\mathrm{Sr}$ & $\mathrm{Ti}$ & $\mathrm{Zn}$ \\
\hline \multicolumn{13}{|l|}{1 day } \\
\hline Mean value & 7.83 & 3.81 & $-^{*}$ & 0.248 & 3.96 & 11.7 & 25.5 & 0.313 & 1.12 & 9.89 & 0.646 & 6.56 \\
\hline Error† & \pm 1.06 & \pm 0.41 & $\mathrm{~N} / \mathrm{A}$ & \pm 0.025 & \pm 0.59 & \pm 1.3 & \pm 3.2 & \pm 0.079 & \pm 0.12 & \pm 1.29 & \pm 0.066 & \pm 0.69 \\
\hline Minimum value & 7.02 & 3.56 & $--^{*}$ & 0.240 & 3.37 & 10.9 & 22.9 & 0.187 & 1.08 & 8.90 & 0.625 & 6.20 \\
\hline Maximum value & 8.89 & 3.96 & $-^{*}$ & 0.257 & 4.55 & 12.5 & 28.2 & 0.431 & 1.17 & 11.1 & 0.665 & 6.82 \\
\hline RSD (\%) & 9.2 & 4.0 & $\mathrm{~N} / \mathrm{A}$ & 2.0 & 11 & 5.0 & 7.3 & 23 & 2.5 & 8.4 & 1.8 & 3.4 \\
\hline \multicolumn{13}{|l|}{7 days } \\
\hline Mean value & 11.0 & 6.51 & 0.149 & 0.302 & 2.20 & 15.2 & 31.5 & 0.342 & 1.35 & 14.1 & 0.765 & 6.58 \\
\hline Error† & \pm 1.3 & \pm 0.92 & \pm 0.044 & \pm 0.045 & \pm 0.6 & \pm 2.4 & \pm 4.4 & \pm 0.059 & \pm 0.16 & \pm 1.6 & \pm 0.082 & \pm 0.68 \\
\hline Minimum value & 9.55 & 5.54 & 0.103 & 0.271 & 1.54 & 12.4 & 26.7 & 0.276 & 1.25 & 10.9 & 0.722 & 6.26 \\
\hline Maximum value & 11.7 & 7.41 & 0.184 & 0.363 & 3.17 & 17.7 & 35.4 & 0.409 & 1.51 & 16.8 & 0.817 & 6.78 \\
\hline RSD (\%) & 6.5 & 10 & 28 & 11 & 26 & 12 & 9.8 & 14 & 6.9 & 5.2 & 4.0 & 2.5 \\
\hline Minimum value & 12.1 & 7.2 & 0.079 & 0.128 & 0.63 & 30.3 & 37.7 & 0.072 & 1.10 & 19.3 & 0.681 & 5.06 \\
\hline Maximum value & 6.52 & 15.6 & 0.221 & 0.460 & 1.68 & 59.0 & 43.5 & 0.721 & 2.06 & 27.3 & 0.902 & 6.92 \\
\hline RSD (\%) & 19 & 27 & 39 & 45 & 36 & 19 & 4.8 & 74 & 20 & 3.5 & 8.4 & 13 \\
\hline $\mathrm{n}$ & 11 & 9 & 11 & 11 & 10 & 10 & 10 & 9 & 11 & 9 & 10 & 10 \\
\hline
\end{tabular}

*Below detection limit.

†Error represents square root of the sum of the squared relative errors of the mean concentration $(1 \sigma)$ and mass.

$\mathrm{RSD}$, relative standard deviation. 
Figure 2 Concentration of metals leached in aqueous solutions with varying $\mathrm{pH}$ after 7 days of soaking.

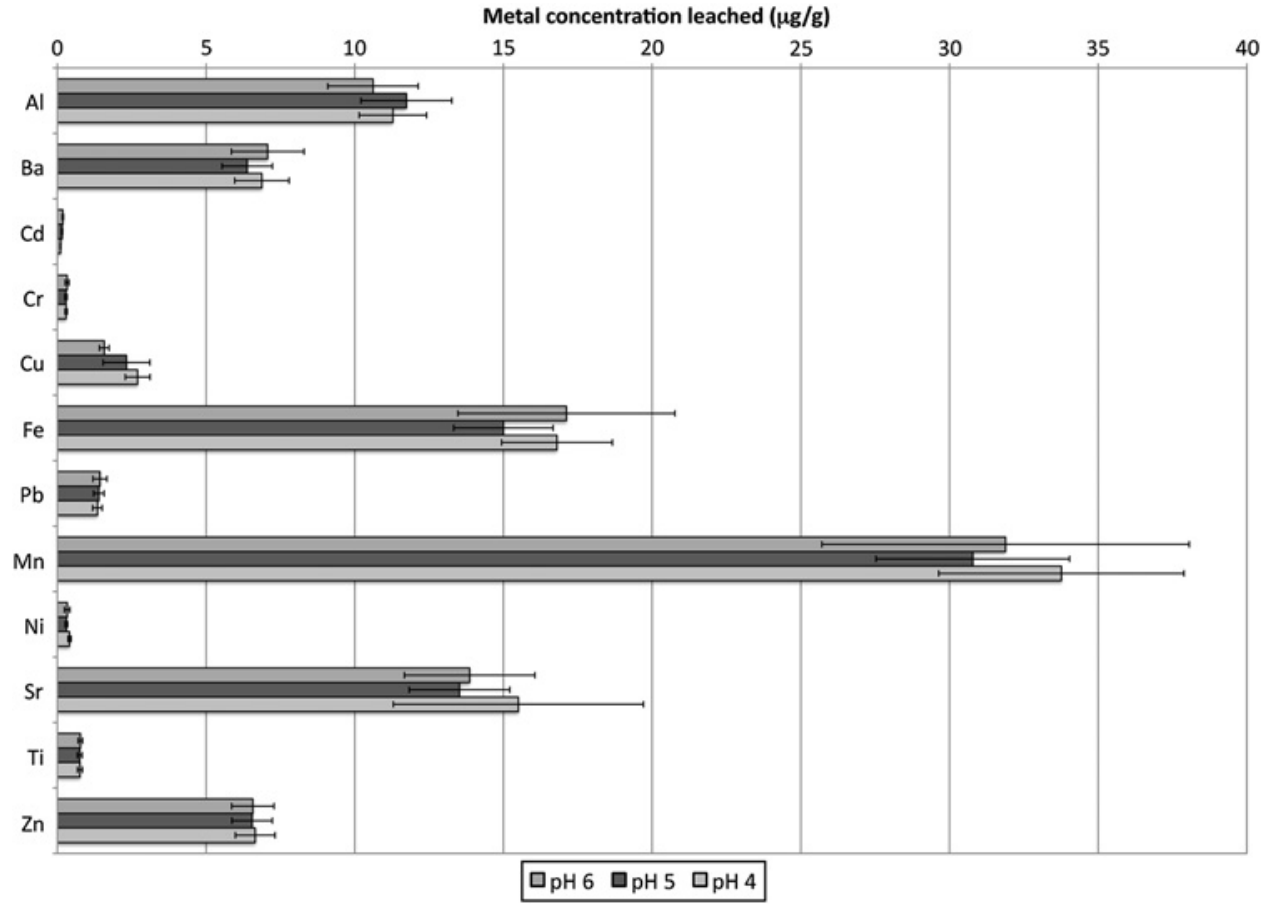

and continual litter cleanup to reduce the magnitude of metal contamination from improperly discarded cigarette butts. In contrast to the metals discussed above, the concentration of $\mathrm{Ni}$, $\mathrm{Pb}$, Ti and $\mathrm{Zn}$ remained relatively unchanged over the 34-day study period. One explanation for this observation is that all leachable metal is released from the cigarette butts after a single day of soaking. For local organisms sensitive to $\mathrm{Ni}, \mathrm{Pb}, \mathrm{Ti}$ and $\mathrm{Zn}$, a rapid release of these metals may have implications for acute biological effects. Because leaching occurred in a closed system, however, these seemingly static concentrations throughout the study period may be due to dynamic equilibrium between the cigarette butt samples and aqueous soaking solution; if so, greater amounts of $\mathrm{Ni}, \mathrm{Pb}, \mathrm{Ti}$ and $\mathrm{Zn}$ may be leached by the continual removal of saturated aliquots of leachate and replacement with fresh water at a rate that exceeds that of equilibrium.

With respect to the metal concentrations previously measured in whole unsmoked American cigarettes, ${ }^{16} 23$ more than half of $\mathrm{Pb}$ and $\mathrm{Sr}$, one-quarter of $\mathrm{Cu}$, and one-fifth of $\mathrm{Ba}, \mathrm{Mn}$ and $\mathrm{Zn}$

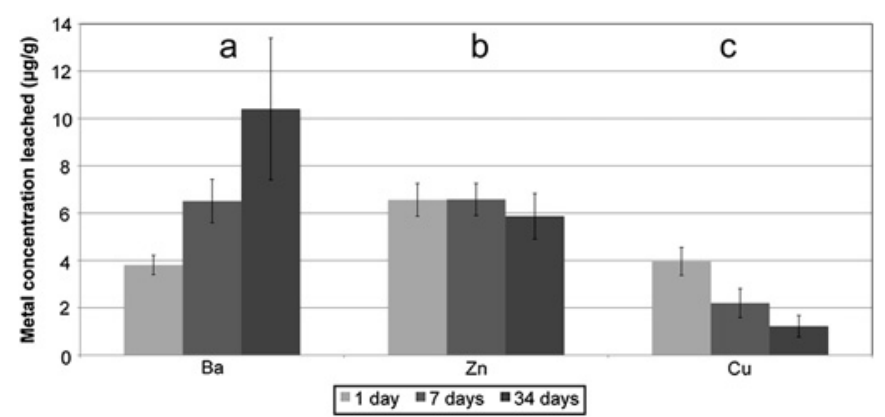

Figure 3 Variable relationships observed between metal concentration leached from smoked cigarette material and soaking time in aqueous solution. A. Increase in metal concentration leached over time. Observed for Ba (shown), Fe, Mn and Sr. B. No significant change in metal concentration leached over time. Observed for $\mathrm{Ni}, \mathrm{Pb}, \mathrm{Ti}$ and $\mathrm{Zn}$ (shown). $\mathrm{C}$. Decrease in metal concentration measured over time. Observed for Al, $\mathrm{Cd}, \mathrm{Cr}$ and $\mathrm{Cu}$ (shown). originally contained in cigarettes may potentially be leached into the environment (table 3). When placed in context of the estimated amount of cigarette butts littered annually (4.95 trillion), ${ }^{1}$ the results of this study indicate that between $0.120 \pm 0.048 \mathrm{~kg}(\mathrm{Cd})$ and $38.1 \pm 8.2 \mathrm{~kg}(\mathrm{Fe})$ may enter the environment each year from cigarette litter alone.

Moriwaki et al. ${ }^{6}$ is thus far the only study known that has also investigated metals leached from cigarette butts. Moriwaki et al. ${ }^{6}$ studied four metals in common with this paper: $\mathrm{Cd}$ $(7.2 \pm 0.70 \mu \mathrm{g} / \mathrm{g})$. These values are approximately $2-7$ times greater than those measured in this study, which is likely due the difference in leaching methods employed. In this study, the metals were allowed to passively diffuse from the cigarette litter. Moriwaki et al. ${ }^{6}$ however, generated leachates by shaking suspensions of cigarette litter in $1 \mathrm{~N} \mathrm{HCl}$ solutions for $2 \mathrm{~h}$. The shaking action is likely responsible for the leaching of greater concentrations of metal from the cigarette litter.

Table 3 Percentage of metal leached from cigarette butts with respect to concentration in whole American cigarettes and annual amount of metal leached from cigarette butts littered worldwide

\begin{tabular}{lclc}
\hline Metal & $\begin{array}{l}\text { Concentration in } \\
\text { whole cigarette, } \boldsymbol{\mu g} / \mathbf{g}\end{array}$ & Percentage leached & $\begin{array}{c}\text { Amount leached } \\
\text { worldwide, }\end{array}$ \\
\hline $\mathrm{Al}$ & $950 \pm 354^{16}$ & $1.2 \pm 0.5$ & $9.26 \pm 1.99$ \\
$\mathrm{Ba}$ & $48.7 \pm 11.2^{16}$ & $21 \pm 8$ & $8.76 \pm 2.52$ \\
$\mathrm{Cd}$ & $0.99 \pm 0.49^{23}$ & $14 \pm 9$ & $0.120 \pm 0.048$ \\
$\mathrm{Cr}$ & $1.78 \pm 2.37^{16}$ & $17 \pm 23$ & $0.254 \pm 0.117$ \\
$\mathrm{Cu}$ & $11 \pm 0.5^{23}$ & $36 \pm 6$ & $3.33 \pm 1.25$ \\
$\mathrm{Fe}$ & $394 \pm 13^{23}$ & $11 \pm 3$ & $38.1 \pm 8.2$ \\
$\mathrm{Mn}$ & $178 \pm 8^{23}$ & $23 \pm 3$ & $33.8 \pm 3.7$ \\
$\mathrm{Ni}$ & $2.75 \pm 0.31^{23}$ & $12 \pm 3$ & $0.288 \pm 0.215$ \\
$\mathrm{~Pb}$ & $2.39 \pm 0.32^{23}$ & $59 \pm 15$ & $1.20 \pm 0.27$ \\
$\mathrm{Sr}$ & $39.6 \pm 14.0^{16}$ & $59 \pm 22$ & $19.7 \pm 2.1$ \\
$\mathrm{Ti}$ & $106 \pm 61^{16}$ & $0.7 \pm 0.4$ & $0.644 \pm 0.084$ \\
$\mathrm{Zn}$ & $35.3 \pm 0.7^{23}$ & $19 \pm 2$ & $5.54 \pm 0.91$ \\
\hline
\end{tabular}

*Calculated using highest mean metal concentration leached and estimated amount of cigarette butts littered annually. $(0.24 \pm 0.60 \mu \mathrm{g} / \mathrm{g}), \mathrm{Cr}(1.8 \pm 0.34 \mu \mathrm{g} / \mathrm{g}), \mathrm{Cu}(21 \pm 0.91 \mu \mathrm{g} / \mathrm{g})$ and $\mathrm{Pb}$ 


\section{What this paper adds}

- The constituents leached from cigarette butts have been identified and quantified by only a few studies. This paper investigates the amount and behaviour of selected trace metals leached from cigarette butts in aqueous solution over a range of soaking periods and $\mathrm{pH}$.

- All metals were detected in the leachates after 7 days of soaking. The results indicate that some metals may be rapidly released into the environment whereas others are leached more gradually from littered cigarette butts.

- This study also finds that the amount of metal leached from cigarette butts does not significantly vary with $\mathrm{pH}$ within the range typical of rainfall.

Leachates of unsmoked cigarettes were investigated in this study to provide background concentrations of the metals of interest and to identify possible instances of contamination. In general, the metal concentrations of the leachates prepared from unsmoked cigarettes were greater than those measured in the leachates prepared from smoked cigarette butts. This result is likely due to the loss of metals in smoke or ash during cigarette combustion, as cigarette smoke and ash are known to contain metals. ${ }^{24-26}$ This trend was observed for all metals except $\mathrm{Al}, \mathrm{Cu}$ and $\mathrm{Ti}$. These exceptions to the trend introduce the possibility of metal contamination prior to sample collection.

Sand and cigarette ash in the butt receptacles were investigated as potential sources of contamination, since they may have adhered to the cigarette wrapping prior to sampling. X-ray diffraction analyses, however, indicate that these materials do not contain minerals bearing the metals studied. Non-crystalline compounds were also detected in the cigarette ash, but their composition could not be identified. Therefore, the adherence of additional ash to the cigarette wrapping cannot be ruled out as a potential contamination source. Sunscreen or lip balm transferred to the cigarette wrapping during smoking is another possible contamination source, as these products have been found to contain many of the studied metals, including $\mathrm{Al}, \mathrm{Cu}$ and $\mathrm{Ti}^{27}{ }^{28}$ Contamination from these sources, however, is not necessarily problematic since cigarette ash, sunscreen and lip balm are often on littered cigarette butts. Another explanation for the higher concentrations of $\mathrm{Al}, \mathrm{Cu}$ and $\mathrm{Ti}$ in the leachates of smoked cigarette material is that these metals are in a more mobile phase in the cigarette filter than in the tobacco. Greater mobility would likely yield greater concentrations leached. Further investigation, however, is required to determine the mobility of metals in filters versus tobacco.

The finding that greater concentrations of metals were in general leached from unsmoked cigarettes than smoked cigarette materials implies that cigarette litter with more remnant tobacco likely causes greater contamination than butts with little or no remnant tobacco. This result calls into question a practice of some environmentally conscious smokers, who scatter remnant tobacco into the environment but keep the filter until it can be deposited into a waste container.

\section{Conclusions}

The results of this research suggest that littered cigarette butts are point sources for prolonged metal contamination. Furthermore, the apparent rapid release of multiple metals from littered cigarette butts increases the potential for acute harm to local organisms. Given the varying responses of organisms to metal contamination, knowledge of the leaching behaviour of metals from cigarette butts is necessary to assess the effect littered cigarette butts have on local biota and the environment in general. With a better understanding of the toxicity of cigarette butts $^{3-5}$ and how contaminants are leached from them (see Micevka et al. ${ }^{3}$ Moriwaki et al. ${ }^{6}$ and this paper), the environmental hazards posed by littered cigarette butts may no longer be a subject of debate.

Acknowledgements We would like to thank Dr Robert Mebane and Dr Steven Symes of UTC for their guidance and valuable suggestions.

Funding This research was funded by the University of Tennessee Chattanooga Department of Chemistry and the University of Chattanooga (UC) Foundation.

Competing interests None.

Contributors Both authors made contributions to this paper to justify authorship.

Provenance and peer review Not commissioned; externally peer reviewed.

\section{REFERENCES}

1. Cigarette Butt Advisory Group. How many filtered cigarettes are deposited into the environment each year? California, 2009. http://cigwaste.org (accessed 4 Oct 2009).

2. Ocean Conservancy. International Coastal Cleanup: 2010 Annual Report. Washington, DC, 2010. http://act.oceanconservancy.org/images/2010ICCReport Release_pressPhotos/2010_ICC_Report.pdf (accessed 24 Feb 2011).

3. Micevka T, Warne M, Pablo F, et al. Variation in, and causes of, toxicity of cigarette butts to a cladoceran and microtox. Arch Environ Contam Toxicol 2006;50:205-12.

4. Register KM. Cigarette butts as litter-toxic as well as ugly. Bull Am Littoral Soc 2000;25.

5. Slaughter $\mathbf{E}$, Gersberg RM, Watanabe K, et al. Toxicity of cigarette butts, and their chemical components, to the marine and freshwater fish. Tob Control 2011;20(Supp 1):i23-i27.

6. Moriwaki H, Kitajima S, Katahira K. Waste on the roadside, 'poi-sute' waste: its distribution and elution potential of pollutants into environment. Waste Manag 2009;29:1192-7

7. Tso TC. Production, Physiology, and Biochemistry of Tobacco Plants. Beltsville, MD: IDEALS, 1990. http://www.longwood.edu/cleanva/ciglitterarticle.htm (accessed 24 Feb 2011).

8. Frank R, Braun HE, Suda P, et al. Pesticide residues and metal contents in flue-cured tobacco and tobacco soils of southern Ontario, Canada 1980-1985. Tobacco Science 1987:21:40-5.

9. Baker RR, Pereira da Silva JR, Smith G. The effect of tobacco ingredients on smoke chemistry, part I: flavourings and additives. Food Chem Toxicol 2004;42S:S3-7.

10. Baker RR, Pereira da Silva JR, Smith G. The effect of tobacco ingredients on smoke chemistry, part II: casing ingredients. Food Chem Toxicol 2004;42S:S39-52.

11. Owens WF. Effect on cigarette paper on smoke yield and composition. Recent Advances in Tobacco Science 1978;4:3-24.

12. Iskander FY. Determination of trace elements in cigarette filter before and after smoking. J Radioanal Nucl Chem 1985;91:191-6.

13. Iskander FY, Klein DE, Bauer TL. Determination of trace and minor elements in cigarette paper by neutron activation analysis. TAPPI Journal 1986;69:134-5.

14. Kabata-Pendias A, Pendias H. Trace Elements in Soils and Plants. 3rd edn. Boca Raton, FL: CRC Press, 2001.

15. Mason CF. Biology of Freshwater Pollution. 2nd edn. Essex, UK: Longman Group, 1991.

16. Iskander FY, Bauer TL, Klein DE. Determination of 28 elements in American cigarette tobacco by neutron-activation analysis. Analyst 1986;3:107-9

17. Iskander FY. Multi-element determination in a Chinese cigarette brand. JRadioanal Nucl Chem 1992;159:105-10.

18. Csuros M, Csuros C. Environmental Sampling and Analysis for Metals. New York, NY: Lewis Publishers, 2002.

19. Kopstein A. Tobacco Use in America: Findings from the 1999 National Household Survey on Drug Abuse. (Analytic Series: A-15, DHHS Publication No. SMA 02-3622). Rockville, MD: Substance Abuse and Mental Health Services Administration Office of Applied Studies, 2001

20. O'Conner RJ, Li Q, Stephens WE, et al. Cigarettes sold in China: design, emissions and metals. Tob Control 2010;19:i47-53.

21. Kemp DD. The Environment Dictionary. New York, NY: Routledge, 1998.

22. National Atmospheric Deposition Program. Hydrogen Ion Concentration as $p H$ from Measurements Made at the Central Analytical Laboratory, 2009. http://nadp. sws.uiuc.edu/maps/Default.aspx (accessed 22 Dec 2010).

23. Bell P, Mulchi CL. Heavy metal concentrations in cigarette blends. Tob Sci 1990;34:32-4. 
24. Benner CL, Bayona JD, Caka FM, et al Chemical composition of environmental tobacco smoke. 2. Particulate phase compounds. Environ Sci Tech 1989;23:688-99.

25. Iskander FY. Cigarette ash as a possible source of environmental contamination. Environ Pollut (Ser B) 1986:11:291-301.

26. Zulfiqar S, Shabbir S, Ishaq M, et al. Metal distribution in Pakistani and foreign brands of cigarette ash. Environ Sci Tech 2006;77:679-86.
27. Zachariadis GA, Sahanidou E. Multi-element method for determination of trace elements in sunscreens by ICP-AES. J Pharm Biomed Anal 2009;50:342-8.

28. Atz VL, Pozebon D. Graphite furnace atomic absorption spectrometry (GFAAS) methodology for trace element determination in eye shadow and lipstick. Atomic Spectroscopy 2009;30:83-91.

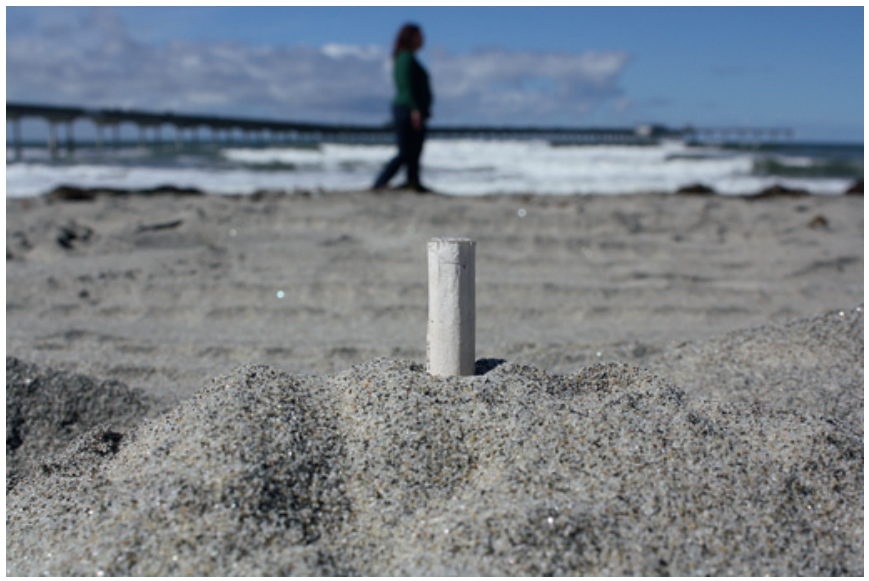

